\title{
IMPLEMENTATION OF THE STATE POLICY REGISTRATION OF PROPERTY RIGHTS USING BENCHMARKING METHODS
}

\author{
Oleg Bolgar', Liudmyla Bogush²
}

\begin{abstract}
The subject of the study is organizational and economic relations that arising in the application of market instruments of regulation of public services for the registration of rights. Methodology. The instrumental and methodological apparatus of the research is formed by the applied methods of economic analysis of the activities of organizations in the service sector, statistical methods, selective observation, the method of economic and mathematical modelling, grouping, generalization, expert assessments, methods of economic theory, marketing, etc. The aim of the article is to develop theoretical and methodological provisions, as well as the development of practical recommendations to improve the process of providing public services for the registration of property rights on the basis of benchmarking. The results of the study showed that the current state of the public services sector is characterized by uneven development and use of modern forms and methods of their management. Improvement of the system of management of public services involves studying the application of best practices, finding solutions for those areas where the gap between the desired and actual state of public services is maximum or exceeds accepted standards. Benchmarking is the most suitable tool for solving these problems. Conclusion. The development of public services for the registration of property rights is a process of consecutive management decisions, based on which methods and ways to improve the effectiveness of their provision are determined. Each stage of the benchmarking process is characterized by a high degree of responsibility of the decisions made, since the wrong choice at one stage will lead to incorrect conclusions and results of subsequent stages. Therefore, when developing a system of public services for the registration of property rights, a consistent algorithm that meets the requirements of management is needed. The benchmarking process is constant and regular. Property rights registration authorities, being monopolists in providing registration services at the regional level, implement the function of satisfying the needs of the population and are financed from the budget. A number of reasons, such as the impersonality of budget funds, indirect interaction between the consumer and the service producer, lack of motivation of employees to meet public needs, lead to the emergence and increase of gaps in the perception of consumers and service producers. In turn, benchmarking is a reliable tool for optimizing the process of providing the services in question and minimizing these gaps.
\end{abstract}

Key words: benchmarking, state registration, property rights, quality of services, service economy, public goods, management tools, market tools.

JEL Classification: M31, 120, H82, G21, P51

\section{Introduction}

The current level of development of socio-economic relations is characterized by the dominant role of the service sector, the intensification of scientific and technological progress and the integration of economic entities. The centerpiece in the development of the service sector is people as consumers and as carriers of human capital, which is the most important factor in economic growth.

The activities of market entities are aimed at maximizing the satisfaction of service needs. The role of the state in the service economy is reduced, on the one hand, to the regulation of the service sector, and on the other hand, to the provision of a wide range of public services to economic entities and citizens.

Government services are of paramount, strategic nature for the economy, but in Ukraine the state as a service provider is considered relatively recently. In today's economy, the development of public services aimed at the formation of public goods; in particular, they include services for the registration of property rights.

The most important factor of production is land resources, without which it is impossible to carry out

\footnotetext{
Corresponding author:

${ }^{1}$ Odessa State University of Internal Affairs, Ukraine.

${ }^{2}$ International University of Economics and Humanities named after academician Stepan Demianchuk, Ukraine.

E-mail: milabogush@mail.com

ORCID: https://orcid.org/0000-0002-2494-6111
} 
economic activity. In the course of the land reform, which was launched about 25 years ago, the land property of citizens, legal entities, the state and local self-government is being formed (Martin, 2015). These processes are accompanied by the need to solve various problems, and therefore the role of state registration services in the economy is growing. One of the peculiarities of state registration services is the content regulation of the provision process, as well as the behavior of the subjects performing these services (Nyhan, 2009).

Public services are necessary for the normal functioning of the economy, while the organizations that provide them are monopolists in their field. In this regard, it is necessary to search for modern market instruments that help to improve both the quality of management of public services and the efficiency of the provision process (Watson, 2017). One of the main such tools is benchmarking. Other market instruments include various economic, managerial, social, marketing and other methods that are used to improve the functioning and development of the sphere under consideration. Among the set of various market instruments in the sphere of state services for the registration of property rights, such tools as elements of the marketing complex, outsourcing, benchmarking, customer surveys, gap analysis can be noted as the most progressive ones. The above determines the importance of the topic of the article, its theoretical orientation and practical significance.

\section{Theoretical substantiation of the necessity and possibility of applying benchmarking to state services for registration of property rights}

The state of the public services sector is currently characterized by uneven development and use of modern forms and methods of their management. Improvement of the management system of public services involves studying the application of best practices, finding solutions for those areas where the gap between the desired and actual state of public services is maximum or exceeds accepted standards. Benchmarking is the most suitable tool for solving these problems.

Benchmarking, as a management tool, is based on identifying examples of best practices, comparing results and processes of government activities, should be carried out continuously and be permanent in public administration.

The interpretation of the term "benchmarking" is not clearly traced in the domestic marketing literature.

In essence, benchmarking is an advanced, strategically oriented methodology of comparative competitive analysis of the organization of business processes (production of goods or services) of an enterprise with similar processes (goods) of other, more successful companies; the concept that involves the unconditional formation of enterprises and organizations of gravitation towards continuous development; the development process based on a constant search for new ideas, development of best practices, techniques and forms of business, their adaptation and further application in their own business practice (Galanter, 1981).

It is believed that the concept of benchmarking originated in Japan in the late 50s of the XX century. The concept of "benchmarking" is compared there to the term "dantotsu", which means "the effort, concern, and concern of the best (leader) to become even better (leader)" (Ohinata, 2004).

Despite the fact that the philosophy of process improvement has existed for quite a long time (including the concept of total quality management, kaizen, reengineering), the concept of benchmarking has become widespread relatively recently.

It should be noted that the interpretation of the concept of "benchmarking" accepted in the scientific literature states its full compliance with the set goal. That is, a certain sequence of methods for managing an enterprise or organization in a competitive environment.

The considered method of service process management allows, on the one hand, to create a set of services, adequate to market conditions, on the other hand, to apply the accumulated experience of effective management. The main goal of benchmarking is to ensure a leading position by improving the quality of services and optimizing business processes (Spendolini, 2013).

In management theory, benchmarking is considered as finding, establishing and analysing the best experience and the possibility of its application. In general, we can recognize benchmarking as an organization management tool. The main idea of benchmarking is to focus on existing successful solutions to such problems. That is, the organization recognizes a more effective solution to the problem by its competitors, both direct and indirect, and the organization's employees are ready for training (Gronroos, 1990).

In service organizations the implementation of benchmarking system can be carried out by setting goals and objectives and performing a number of functions.

The goals of benchmarking in the field of public services can be:

- increasing the degree of citizens' satisfaction by improving the quality of service and reducing the time of processes;

- optimization of the level of costs for the implementation of public services (reduction of budget expenditures at various levels);

- strengthening of positions in the system of state organizations; 
- justification of the implementation of innovative activities in various areas.

Then the tasks of benchmarking may be as follows:

- determination of areas of research that correspond to the set goal;

- choice of research area: internal, external structures, one or more areas of activity, national, international experience;

- identification of research objects whose experience may be of value to the organization;

- establishment of comparison criteria consistent with the goals set;

- setting up a productive relationship with a benchmarking counterparty;

- obtaining reliable information;

- choice of adequate methods for analysing the information received (Stewart, 2004).

This scheme characterizes the cyclical nature of the benchmarking process: in the case of a cycle interruption, the result cannot be long-term. At the same time, it is necessary to note the consistent and mandatory nature of all actions, their purposefulness.

The importance of benchmarking in the public sector is primarily that the conclusions derived from it can indicate directions and create incentives for innovative changes similar to those sent by the market in the private sector. The practice of results management around the world shows that simply monitoring results cannot lead to significant improvements in efficiency and productivity. For this reason, benchmarking is one of the most specific tools of this theory. In particular, it allows the application of performance indicators, the formation of systems incentives and "conditional competition", which are necessary for the system of public services in the country (Forsythe, 2011).

As the global experience shows, public sector organizations have recently been increasingly turning to benchmarking their services. In the U.K. public sector, benchmarking has been recognized as a powerful tool for improvement and a way to implement the systematic changes needed to deliver modern public services (Le Grand, 2019).

It was also recognized that efficient public services play an important role in enhancing the competitiveness of the private sector by reducing the bureaucratic burden on business.

Benchmarking is a way to create the incentives necessary for change in the implementation of both key and non-key activities to raise the standard of public services through the dissemination of best practices (Needham, 2011).

In Europe, benchmarking is used as a tool to make improvements in the work of both public and commercial organizations, as a means of improving the competitiveness of the European economy as a whole.
In Canada, the system of benchmarking municipal services of the province of Ontario has become widespread. This system analyzes information about such parameters of services as efficiency, performance, public perception in the context of individual processes of their provision (Watson, 2017).

In the US, the most significant benchmarking initiatives include projects in North Carolina (a joint project of 35 state municipalities), Oregon (Oregon Options), Minnesota (Minnesota Milestones) and Florida (Florida benchmarks). Common to these projects was the emphasis on benchmarking of financial indicators (efficiency, unit cost) (Fernandez, 2016).

In the 2000s, Virginia Polytechnic Institute and State University did some very interesting research at the municipal level regarding zoning and building permit services. The system of benchmarking indicators includes both indicators of unit cost and indicators derived from the survey, characterizing customer satisfaction with the process of service delivery (clarity of procedure, availability of staff, clarity of information, time of service provision) (Seybert, 2006).

In a market environment, the process of implementing benchmarking faces obstacles that can be successfully overcome in the public sphere. It is in the area of public services the use of benchmarking has considerable potential due to the public status of service producers, the directive nature of their orders, the commonality of the system of organization of public services (Spendolini, 2013).

It is customary to distinguish five main types of the benchmarking process (some scientists distinguish a larger number of types):

- internal benchmarking;

- external competitive benchmarking;

- external intra-industry benchmarking (combined);

- external cross-industry benchmarking;

- combined cross-industry and external benchmarking.

\section{Typology of modern benchmarking as a method of state registration of property rights}

As James H. Harrington, "There is no best type of benchmarking. Each of the different types (internal, external competitive, external industry, external cross-industry, and a combination of external and internal) has advantages and disadvantages that must be considered".

It should be noted that there is a fundamental difference regarding the processes of internal and external benchmarking. As for internal benchmarking, it can be noted that it is aimed at finding common elements of similar activities and determines which of them should be standardized and applied in the organization as a whole. External benchmarking is aimed at establishing communication between market 
participants and, in fact, is a market research. In public services, benchmarking can be both external and internal.

It is also customary to distinguish certain forms of benchmarking.

Corporate benchmarking is point - based and, most often, one-time in nature; it focuses on one specific process that has been identified as problematic in advance (identification occurs by expert means). The goal is to find an optimization solution in the problem area.

An advanced approach to benchmarking - tracking progress against a system of exogenously defined goals. It is used as part of the implementation of the strategic planning cycle. The purpose - the formation of information about the achievement of the goals and objectives of the activities of the subject of benchmarking.

Benchmarking of performance is a comparison of achieved values of indicators with adequate external standards (professional standards, national statistics data, the results of the activities of similar institutional units in terms of parameters). Its purpose is to evaluate the performance of organizations controlled by the subject of benchmarking, providers of public services (Wang, 2015).

To assess the quality of public services, benchmarking can be considered the most applicable. A number of researchers call this form statistical benchmarking. This form of benchmarking should be understood as evaluation, benchmarking and transfer of managerial innovations, which are based on the analysis of the system of performance indicators.

Performance benchmarking is characterized by minimization of unit costs in its cyclic use. It can be carried out annually without significant revision of the conditions and mechanisms of its implementation.

The other forms of benchmarking considered involve creating all the elements anew in each cycle. We can say that performance benchmarking is a single organized approach to the analysis of various activities in public administration.

The quality of service delivery in a formalized form is expressed as a set of performance indicators. This brings clarity and incontestability of facts for the participants of the benchmarking process about the achievement of a certain level of performance and the possibility of its improvement on the basis of best practices.

\section{Organization directions of modern benchmarking as a method of state registration of property rights}

We will analyze possible ways of organizing benchmarking in the sphere of state services for the registration of property rights.
In the first method of benchmarking, the state agency for registration of property rights acts as the coordinator of the process. At the same time, it develops a questionnaire, conducts an assessment and provides data to other participants in the benchmarking process. The cadastral organizations do not contact each other. The coordinator provides information to the participants for decision-making.

The second method assumes parity of all participants in the benchmarking process within their rights and obligations to provide, collect and exchange information. Development of the questionnaire and evaluation of the results are carried out collectively. In this case, the accounting bodies constantly exchange information, and the benchmarking process itself is continuous (Stapenhurst, 2009).

The third method is a combination of the functions of the state body for the registration of property rights as the coordinator of the process, on the one hand, and the activities of accounting organizations, on the other hand, in a joint study of research areas. Local accounting bodies develop a questionnaire, there is an ongoing exchange of information between them, and the state body evaluates and interprets the data, as well as provides training on benchmarking mechanisms.

The fourth method involves the creation focus groups consisting of the subjects of the benchmarking process. Differentiation of composition of participants is determined by chosen direction of research. In benchmarking the data are pre-selected and processed according to this option. The exchange of information between accounting bodies is limited. The process can be coordinated by both state and regional bodies, if they have the necessary experience.

The definition of the method of benchmarking organization is determined by its ultimate goal. The first two methods discussed above provide for a greater concentration of benchmarking management functions in a central unit; in turn, the last two methods, on the contrary, involve mutual coordination of participants, and they can be considered more developed (Monro, 2003).

Its own algorithm characterizes each of these options for benchmarking public services for the registration of property rights. However, it should be noted that all of the options considered, and thus the algorithms for their implementation, differ from each other only in terms of the organization of the process, while its content in most cases is the same.

The first option of organizing the benchmarking process is centralized. It is characterized by the following algorithm.

Stage 1. Involves the creation of an "agent" for benchmarking, developing performance indicators, organizing and controlling the collection, analysis, processing of information that arises during this process. In this case, the state body acts as an "agent". 
Stage 2. The activity related to performance measurement has a certain set of limitations, most thoroughly discussed by Stewart and Walsh (Stewart, 2004).

Among these limitations, there are general and specific ones that are specific to benchmarking, since they are based on solving the problems of the relevance of information and confirming its significance and objectivity by the participants of the benchmarking process.

Since the initiator of benchmarking is interested in improving, first, management processes, management quality indicators should take place in the system of indicators simultaneously with indicators of socioeconomic efficiency.

The formation of a system of performance indicators is central to the design of benchmarking systems. It should ensure their maximum quality and applicability for solving the tasks at hand.

Stage 3. Questionnaire creation and provision of data to the participants of benchmarking. At the same time, benchmarking participants are not in contact with each other, but only with the "agent" of the benchmarking process.

Stage 4. At this stage, the system of indicators is coordinated with the participants of the benchmarking process. This is due to the mutual influence of indicators in one area, which can lead to difficulties in the process of data analysis, as well as in the formation of aggregated performance indicators.

In case of inconsistency of the indicator system, it is subject to correction by the "agent" of the benchmarking process.

Stage 5. Making the order of management decisions in the benchmarking system.

The benchmarking system must have the properties of stability and efficiency, for which it must be stable in organizational terms.

The decision to formally or informally implement a benchmarking system is made by each participant based on an analysis of a number of provisions. In other words, one of the essential factors of system stability is the primacy of managerial decisions.

Stage 6. Establishment of relationships between the results of benchmarking and the amount of incentives for the best "suppliers" of public services. Provision of additional financial resources is necessary to encourage participants of the process, which are the best among the rest, as well as to compensate their costs associated with the collection and analysis of information, implementation of technologies that improve the quality of services.

This statement shows the scale of the implementation of the benchmarking mechanism and its interaction with the legal and budgetary system of the state. As a result, it is necessary to achieve clarity within the framework of two directions:
1) The legal status of the benchmarking system and its indicators;

2) Determining the relationship between the achieved values of indicators and the amount of budget allocations.

Stage 7. Data collection by the "agent" of the benchmarking process from each of the participants involves the accumulation of baseline data, calculations, internal audit of the effectiveness of activities and individual processes.

Stage 8. Determination by the "agent" of the best practice in the benchmarking system and the volume of incentives (Greener, 2009).

The relationship between the achieved values of performance indicators and the volume of incentives depends on the management structure of public service producers, including their obligations regarding the quality and efficiency of their activities.

The benchmarking process is regular. This helps achieve certainty in addressing the two issues noted above (step 6). The final provision should be a decision on how to integrate the benchmarking process into the government's both funding and its plan system.

The second option for organizing the benchmarking process is one of the decentralized ones presented. This option differs from the previous one, first, in that there is no "agent" for conducting the benchmarking process. It is necessary to recognize the fact that the considered variant is the most progressive, however, in connection with absence in this system of any material incentives, it can be applied only in a highly organized system of public services. It is characterized by the following algorithm.

Stage 1. Such an algorithm is an agreed decision by the participants of the benchmarking process to conduct it. All participants in the benchmarking process have equal rights and responsibilities.

Stage 2. Is similar to stage 2 of the first option and consists in creating a system of correct performance indicators.

Stage 3. Involves the preparation of a questionnaire by the participants of the benchmarking process on the principles of consistency and openness.

Stage 4. At this stage, the system of indicators is coordinated with the participants of the benchmarking process. In case of inconsistency of the indicator system, it is subject to correction by the participants of the benchmarking process.

Stage 5. It is identical to this stage of the first option.

Stage 6. Data exchange between all participants in the benchmarking process: each of the participants must collect the necessary background information, conduct internal audits of performance and individual processes and provide them to the other participants in the process.

Stage 7. Identification of best practices in the benchmarking system by participants. The complexity 
of this stage lies primarily in the fact that state services for the registration of property rights are provided by one body in each administrative unit of the state. This circumstance determines the monopolistic position of the provider of public services, and, consequently, the motivation in this option of organizing the process of benchmarking can only be the desire to improve the quality of services provided (Daft, 2012).

The benchmarking process is an ongoing one that facilitates the introduction of benchmarking into the activities of public service providers.

In the organization of the third variant of the benchmarking process, as in the case of the first variant, the role of the state body is noticeable. It is characterized by the following algorithm.

Stage 1. Involves the definition of a coordinator for benchmarking, who develops performance indicators, as well as collects, processes, and analyzes information obtained in the benchmarking process. The state body acts as the coordinator.

Stages 2-5 are identical to the first two options for benchmarking. The only difference is in the implementation of stage 3 . The benchmarking participants compile the questionnaire. At the same time, the benchmarking participants exchange information with each other, and the coordinator of the benchmarking process evaluates and interprets the data.

Stage 6. Data collection by the benchmarking process coordinator from each of the participants includes providing them with baseline data, conducting internal audits of performance and individual processes. If necessary, the coordinator provides training on benchmarking procedures.

Stage 7. The coordinator identifies best practices in the benchmarking system. This option also does not provide financial incentives for participants in the benchmarking process, so the incentive can only be the desire to improve the quality of services (Brown, 2016).

The benchmarking process is also constant and regular.

The fourth option of organizing the benchmarking process involves the formation of focus groups of process subjects, depending on the direction of research. The following algorithm characterizes it.

Stage 1. Involves the definition of a coordinator for benchmarking, who develops performance indicators, as well as collects, processes, and analyzes information obtained in the benchmarking process. The coordinator can be a federal or regional body, if it has the necessary experience.

Stage 2. At this stage, focus groups of participants in the process are determined.

Stage 3. Preparation of the questionnaire by the participants of the corresponding focus group. At the same time, the participants of the benchmarking focus group exchange information with each other, and the coordinator of the benchmarking process evaluates and interprets the data.

Stages 4-5 are identical to the other options for organizing benchmarking.

Stage 6. Data collection by the benchmarking process coordinator from each of the participants includes providing them with baseline data, conducting internal audits of performance and individual processes. If necessary, the coordinator provides training on benchmarking procedures.

Stage 7 . The coordinator determines the best practices in the benchmarking system. This option does not imply financial incentives for participants in the benchmarking process. This stage also reveals how effectively and correctly, the focus group participants were selected. If the composition of focus groups is not effectively determined, it may be revised (Calhoun, 2014).

\section{Conclusion}

The benchmarking process is constant and regular.

Property rights registration authorities, being monopolists in provision of registration services at the regional level, implement the function of satisfying the needs of the population and are financed from the budget. A number of reasons, such as depersonalized budget funds, mediated interaction between the consumer and producer of services, lack of motivation of employees to meet public needs, lead to the emergence and increase of gaps in the perception of consumers and producers of services.

In turn, benchmarking is a reliable tool for optimizing the process of providing the services under consideration and minimizing these gaps.

Thus, during the research the current state of the sphere of services was analyzed. As a result, it was revealed that it is caused by a number of factors of economic life. First, we are talking about the globalization of economic life in a crisis and the informatization of management processes. These objective phenomena determine the state of the modern business sphere, including the sphere of providing business services.

A feature of today's service economy is the changing role of information in the process of providing, managing and consuming services. Information is becoming an integral part of the service in one capacity or another. Information services become an integral part of the basic service offerings of non-core sectors of the economy; they are an obligatory element of a set of additional services; information (additional information services) can form the commitment of consumers to a particular service organization; information is an integral element of the service 
environment of the service; information systems in the service sector act as a means of service performance.

It turns out that most authors define a service through some sign (or several signs). From our point of view, there are exceptions in the diverse list of services that do not meet one or two of the criteria specified in the authors' definitions. By service we mean the action aimed at satisfying the needs of the client, which in general has the properties of immateriality, individuality, inseparability from the performer and non-preservability.

The main problem in the process of managing public services is determining their rational scope, from the point of view of society. The process of creating government bodies and empowering them to perform certain public services is subjective and usually carried out by representatives of the dominant ideology in society. Decisions about the level of public services can be made on the basis of such factors as the influence of the church, the influence of culture, and the influence of mentality.

We consider the definition of state activity as a service activity to be of fundamental importance, emphasizing that in today's service economy, absolute priority is given to the consumer. Therefore, public sector services should primarily focus on customer needs: to offer and implement services in accordance with customer requirements in terms of basic, additional services, service environment.

In the course of the study, the mechanism of benchmarking as a management tool was considered, which is based on identifying examples of best practices, comparing the results and processes of the activities of the country's authorities. It is revealed that the process of benchmarking should be carried out continuously and be permanent in the framework of public administration.

For organizations that provide public services, four options were proposed for organizing the benchmarking process with different degrees of involvement of state and regional authorities. The most progressive form of organization of this process is the decentralized version without state intervention, but it is possible only in highly organized systems, the participants of which seek to improve the quality of services provided without additional incentives. The most possible options for organizing benchmarking can be options with the participation of the management body in the status of an "agent" or coordinator of change.

The development of public services for the registration of property rights is a process of consecutive managerial decisions, based on which methods and ways to improve the effectiveness of their provision are determined. Each stage of the benchmarking process is characterized by a high degree of responsibility for the decisions made, because a wrong choice at one stage will lead to incorrect conclusions and results of subsequent stages. Therefore, when developing a system of public services for the registration of property rights, a consistent algorithm that meets the requirements of management is needed.

\section{References:}

Brown, T. (2016). Learning from experience and managing the transaction costs of internal and contract service delivery. Paper presented at 2016 APPAM fall conference in Madison.

Calhoun, J. W. (2014). Administrative office management: complete course. Cengage Learning.

Daft, R. L. (2012). Management. South-Western, Cengage Learning.

Fernandez, S. (2016). Managing successful organizational change in the public sector. Public Administration Review. Mar./Apr., pp. 168-176.

Ferreira, E. J. (2009). Administrative management. 2nd ed. Lansdowne: Juta Academic.

Forsythe, D. W. (2011). Pitfalls in designing and implementing performance management systems. Quicker? Better? Cheaper?: managing performance in American government. The Rockfeller Institute Press.

Galanter, M. (1981). Justice in many rooms: courts, private ordering, and indegenous law. J. of Legal Pluralism, $19,1-47$.

Greener, I. (2009). The Consumer in Public Services: Choice, Values and Difference. The Policy Press.

Grief, A. (1993). Contract enforceability and economic institutions in early trade: the maghribi trade coalition. American Economic Review, 83(3), 525-548.

Gronroos, C. (1990). Service management and marketing: managing the moment of truth in the service sector. Cambridge, Mass: Marketing Science Institute.

Le Grand, J. (2019). The other invisible hand: delivering public services through choice and competition. Princeton: Princeton Univ. Press.

Martin, S. (2015). Multiple public service performance indicators: toward an integrated statistical approach. J. of Public Administration Research and Theory, 15, 599-613.

Monro, D. (2003). The role of performance measures in a federal-state context: the examples of housing and disability services. Australian J. of Public Administration, 62(1), 70-79. 
Needham, C. (2011). Personalizing public services: understanding the personalization narrative. Bristol: The Polity Press.

Nyhan, R. C. (2009). Comparative performance measurement: A primer on data envelopment analysis. Public Productivity and Management Review, 22(3), 348-364.

Ohinata, Y. (2004). Benchmarking: the Japanese experience. Long Range Planning, 27(4), 48-53.

Poister, Th. H. (2003). Measuring performance in public and non-profit organizations. Jossey-Bass.

Stewart, J. (2004). Performance measurement: when performance can never be finally defined. Public Money and Management, 45-49.

Seybert, J. A. (2006). Benchmarking: an essential tool for assessment, improvement, and accountability. San Francisco: Jossey-Bass.

Spendolini, M. J. (2013). The benchmarking books. 2nd ed. N.Y.: Amacom Books.

Stapenhurst, T. (2009). The benchmarking book. Oxford, UK: Butterworth-Heinemann.

Watson, G. H. (2017). Strategic benchmarking reloaded with six sigma: improving your company's performance using global best practice. Hoboken, New Jersey: John Wiley \& Sons, Inc.

Wang, X. H. (2015). Hypotheses about performance measurement in counties: findings from a survey. J. of Public Administration Research and Theory, 11, 403-428. 